\title{
A cidadania evidenciada na diferença
}

Eliana Prado Carlino*

\section{Resumo}

Ao investigar os processos pelos quais alfabetizadoras bem sucedidas tornamse cidadãs e ao ouvir a diversidade e a riqueza de suas histórias de vida e de formação, configurou-se a possibilidade deste trabalho, cuja intenção é evidenciar as vozes de dois sujeitos com Síndrome de Down e seus processos de constituição como cidadãos. Esses sujeitos foram trazidos nos relatos das professoras que, ao contarem suas histórias de construção pessoal e profissional os colocaram como constituintes delas. Assim, é trazido neste trabalho um pouco do universo de dizeres e percepções no qual esses sujeitos elaboram suas referências e compreensão do mundo e procuram atuar como cidadãos. $O$ trabalho está apoiado nas concepções de linguagem de Vygotsky e de Bakhtin que defendem a idéia de que o coletivo e o social estão imbricados no individual, portanto, a história de um sujeito revela a de muitos, já que há uma profunda ligação entre história individual e história social na construção do mundo subjetivo. Desse modo, os dizeres expressos pelos sujeitos desta pesquisa não podem ser considerados estritamente individuais porque a enunciação é de natureza social e apesar de serem expressões individuais apontam para uma realidade coletiva que evidencia por parte das pessoas com deficiência suas reais necessidades e possibilidades de participação e de intervenção social.

Palavras-chave: Cidadão; Deficiência; Linguagem.

\section{Citizenship displayed by disabled people}

Abstract

By investigating the processes by which successful teachers become activate citizens and by listening to the diversity and richness of their life and formation stories, this work became possible. Its aim is to display some of the utterances of two Down Syndrome individuals and their active-citizenship activities. Their stories were told in the reports of two teachers when describing their personal and professional history, and were considered to be an integral part of it. Thus, some of the utterances and perceptions with which these two individuals elaborate their references, their worldview and their active-citizenship activity are evidenced in this paper. This article is based on the language conceptions of Vygotsky and Bakhtin who defend the idea that the group and the social mentality are ingrained

\footnotetext{
* Professora de Psicologia na Divisão de Ensino da Academia da Força Aérea Brasileira, Pirassununga, São Paulo, Brasil.
} 
in the individual. Hence, the history of one person reveals that of many others, since there is a deep link between the individual and the social in the formation of a subjective worldview. As a result, it can be easily seen that the utterances expressed by the participants in this research cannot be considered strictly individual because enunciation is social in nature. Despite the fact that the utterances are those of individuals, they manifest a collective reality. This demonstrates the real advantages and possibilities that deficient people get from their participation and intervention in society.

Keywords: Citizen; Deficient; Language

Ainda que falar sobre inclusão pareça um tema já desgastado, podemos considerá-lo não esgotado e com muitas arestas, principalmente, se pensado da perspectiva das pessoas com alguma deficiência.

Alguns trabalhos (DE CARLO, 1999, KASSAR, 1999 e PADILHA, 2005) merecem referência porque apresentam o tema da diferença ${ }^{1}$ na perspectiva das pessoas consideradas diferentes e as posicionam como protagonistas de uma história que ao longo dos tempos as têm emudecido.

De Carlo (1999) coloca em cena e nos permite ouvir adultos residentes de uma instituição para deficientes mentais, que como tantas outras, os submetem a muitas formas de silenciamento.

Kassar (1999), ao realizar um trabalho empírico com jovens de uma instituição especial, discute aspectos da constituição social desses sujeitos, dando-lhes voz e evidenciando seu processo de construção que ocorre dentro e fora da sala de aula, mas que, com certeza, também é mediado pela escola "especial" e pelos discursos nela veiculados.

Já Padilha (2005) evidencia a trajetória de uma garota com diagnóstico de deficiência mental grave e apresenta sua constituição como sujeito simbólico e seu avanço significativo em termos de funções psicológica superiores.

Neste trabalho falaremos de I. (26 anos) e F. (45 anos), ${ }^{2}$ sujeitos com Síndrome de Down, cujas vozes são trazidas neste trabalho por educadoras que dele participaram e, que, ao contarem suas histórias de construção pessoal e profissional os colocaram como constituintes delas.

A ideia inicial era investigar os processos pelos quais alfabetizadoras bem sucedidas tornavam-se cidadãs, porém, a partir da diversidade e da riqueza dessas histórias foram-se configurando novas possibilidades que nos instigaram a pensar na constituição da cidadania daqueles que apareciam nos relatos dessas professoras. 


\section{A história de um sujeito revelando as histórias de muitos}

Na constituição do sujeito se entrecruzam aspectos individuais e sociais - é uma síntese que ao mesmo tempo em que nos identifica e nos singulariza também nos iguala a muitos outros. É o mundo interior que se constitui em consonância com as experiências vividas no mundo social e cultural. Isso torna as pessoas comuns e, ao mesmo tempo, únicas, porque a apropriação do mundo exterior que cada uma faz é realizada de modo singular.

Buscamos em Bakhtin e em sua visão sobre a linguagem como constitutiva do humano, elementos para que possamos apoiar nossa idéia de que o coletivo e o social estão imbricados no individual.

Em toda enunciação, por mais insignificante que seja,
renova-se sem cessar essa síntese dialética [...] entre a
vida interior e a vida exterior. [...] Cada palavra se apre-
senta como uma arena em miniatura onde se
entrecruzam e lutam os valores sociais de orientação
contraditória. A palavra revela-se, no momento de sua
expressão, como o produto da interação viva das forças
sociais. (BAKHTIN, 2004, p. 66 )

Dessa forma, podemos afirmar que ao falarmos de um único sujeito estamos falando de muitos outros. Assim, foi a partir de relatos de histórias de vida e de formação profissional que empreendemos este nosso trabalho. E foi nesses relatos feitos por professoras que pudemos apreender, por meio do olhar e do dizer delas, um pouco do modo de constituição de pessoas com deficiência $^{3}$ e sua inserção nos processos sociais.

Vygotsky (1995), principal representante da abordagem histórico-cultural, ao discutir sobre a formação da identidade afirma que é por meio do que significa para os demais que cada sujeito pode se ver e se relacionar consigo mesmo; é também por meio de como os outros significam o que dizemos que nos situamos em determinados lugares nos processos interlocutivos. Podemos ter nossas falas confirmadas/rejeitadas; reconhecidas/ignoradas; qualificadas/ depreciadas e assim por diante.

Desse modo, nas tramas interlocutivas há sujeitos que se constituem e constituem outros, em práticas socioculturais. Há, portanto, uma profunda ligação entre a história individual e a história social na construção do mundo subjetivo. É uma história construída por cada um na interação com os outros.

Tal vertente caracteriza o homem como um ser simbólico e um ser de relações. O signo funcionando e sendo produzido nas relações entre as pessoas vai constituindo modos de pensar, sentidos e significados. Vygotsky (1989) defende que o sujeito com algum tipo de deficiência não é menos desenvolvido do que os outros, apenas se desenvolve de outro modo e, portanto, sabe pensar e operar com abstrações. 
Tanto Vygotsky quanto Bakhtin preocuparam-se com a significação colocando a dialogia como princípio que marca as interações humanas, afinal, o sujeito está o tempo todo na linguagem, na interação e no diálogo com o outro. Assim, a linguagem, que começa no campo interpessoal, ao entrar em funcionamento, afeta de diversas maneiras a instância intrapessoal.

Desse modo, os dizeres de cada sujeito que se expressam por suas falas não podem ser considerados estritamente individuais porque não podem ser explicados a partir "das condições psicofisiológicas do sujeito falante. A enunciação é de natureza social" (BAKHTIN, 2004, p. 109). Assim, mesmo que as palavras sejam ditas ou exteriorizadas individualmente, por cada participante das interlocuções, por cada organismo individual, elas não são individuais em sua gênese.

É a partir dessa perspectiva teórica que trazemos aqui as falas de duas pessoas com Síndrome de Down, realçando que elas se constituem nesse universo de discursos, dizeres e percepções, e nele vão elaborando suas referências e compreensão do mundo, atuando ou não como cidadãos com direito à expressão e à participação social.

I. e F. não se conhecem e nunca se encontraram, porém, os seus dizeres convergem para um dos muitos sentidos construídos socialmente sobre a pessoa considerada com deficiência - sua "incapacidade" para dizer e para ser ouvida. Neste caso, apesar de suas histórias serem diferentes há muitas coisas que os aproximam e os tornam parecidos com tantos outros sujeitos cujos dizeres não estão colocados aqui.

Realizamos este trabalho com a intenção de evidenciar a leitura de mundo feita por sujeitos caracterizados como deficientes e como eles se mostram cidadãos, ainda que por meio de tentativas, muitas vezes, frustradas e não reconhecidas pelo seu entorno social.

\section{"Porque eu não me formo nunca?" - Tentativas para o exercício da cidadania}

Não podemos nos esquecer de que há circunstâncias históricas da educação especial que ajudam a entender sua forma de atuar e de se considerar autoridade no assunto quando ele se refere às pessoas com algum tipo de deficiência; e por isso, estão acima de qualquer suspeita em relação às suas práticas educacionais.

Durante muito tempo, o trabalho realizado com essas pessoas esteve sob a "guarda" de um sistema de ensino à parte, considerado especial. Neste sentido a educação dessas pessoas sempre esteve sob a responsabilidade de equipes altamente especializadas. Sempre foram técnicos (psicólogos, fonoaudiólogos, terapeutas ocupacionais e outros) e não professores (a não ser 
os também altamente especializados) os responsáveis pela educação dessas pessoas. Assim, esse trabalho foi muito mais marcado pelo enfoque médico e psicológico do que pelo educativo ou pedagógico.

Com o advento das propostas de inclusão um grande embate ocorreu no sentido de definir a quem caberia a responsabilidade no atendimento dessas pessoas - surdas, cegas, ou com limitações físicas e intelectuais. As escolas regulares considerando sua inadequação e pouca formação, não se achavam aptas para a tarefa (FERREIRA e FERREIRA, 2004; KASSAR, 2004); pais e alunos desejosos por fazer valer seus direitos de acesso à escolaridade denominada comum buscavam a vigência da lei, enquanto profissionais das escolas especiais reivindicavam seu direito no trabalho e atendimento dos alunos denominados "especiais" dada a sua formação e especialização para a tarefa. Por sua vez, alunos considerados "alvos da inclusão" ou pessoas com deficiência sequer eram consultadas ou ouvidas a respeito de algo que lhes afetava diretamente (GLAT, 2004; NEVES, 2003), até porque a visão que se institucionalizou acerca delas é a de pessoas infantilizadas e sem condições de fazer suas próprias opções.

Sendo assim, muito pouco ou quase nada se abordou sobre a inclusão a partir da perspectiva das escolas especiais, a quem historicamente se destinou a formação ou o cuidado dessas pessoas.

Por esta razão queremos problematizar essas questões na tentativa de evidenciar a voz falada (mas quase nunca ouvida) de pessoas cujas diferenças as colocam em posição de desvantagem social e educacional. Neste sentido, algumas questões se explicitam para nós:

- Por que não pensar o processo de inclusão acontecendo a partir da própria escola especial?

- Como essas pessoas, quase em sua maioria, sem acesso à leitura e à escrita, significam o mundo e são significadas por professores, técnicos e especialistas que com elas ou sobre elas atuam e exercem seus saberes e fazeres profissionais?

- O que as pessoas com Síndrome de Down pensam e falam a respeito da escola, das relações de trabalho, das relações afetivas, enfim, do mundo? E como são (ou não) ouvidas?

F. (45 anos), com Síndrome de Down, estuda há pelo menos 40 anos numa escola especial. Sua grande frustração é não ter sido alfabetizado. Uma das professoras participantes da pesquisa fala sobre ele:

Gérbera: "Ele tem 45 anos, o prognóstico dele foi dos mais terríveis, não iria andar, não iria falar, não iria ser... [...] poucas propostas de alfabetização... mas nunca se acreditou nesta possibilidade, não se investia no potencial dele, eram propostas que vinham sem muitas tentativas de se adequar à sua 
realidade ou à algum interesse seu, então aí, acabavam diluindo e terminavam [...] isso frustrava um pouco; aí encerrava a proposta de alfabetização e continuava oficina, madeira, lixa, só atividades manuais. Uma fala recorrente de F. é: 'mas porque eu sou analfabeto? Eu quero aprender. Eu não sei ler, não sei escrever, não consigo juntar sílabas'”.

"A alguém de sua família cuja formação se deu em nível de pós-graduação, ele insiste em questionar: "Como é que você se sente formada? Por que eu não me formo nunca? "Porque naquela prisão (como ele, geralmente, se refere a sua escola) não tem faculdade."

"A escola em que F. está estabeleceu, por um tempo, um contrato com uma empresa da cidade que pagava (simbolicamente) para os alunos confeccionarem certo trabalho. F. desejava comprar algumas coisas com aquele dinheiro, mas a família sempre Ihe explicava que aquilo não era suficiente para seus desejos de compra, pois era muito pouco diante do valor dos objetos que ele desejava adquirir. Um dia a escola foi visitada pelo gerente da empresa e $F$. prontamente indagou-Ihe: 'Ah, você é o nosso patrão? Nossa, mas você paga uma miséria, não!?"”

Hortência: "Bom, já entendeu a relação de patrão."

Violeta: "Acho que ele entendeu tudo, o que era dele de direito. Acho que ele tinha toda a razão do mundo..."

Em outro episódio F. questiona o fato de não poder receber o seu pagamento, o que era feito por seus pais, a pedido da escola. "Não sei porque tenho que levar meu pai e minha mãe lá pra receber, eu é quem estou trabalhando, eu não sou criança."

A escola explicava que isto era feito por precaução. Mas ainda assim, ele dizia: "Por que não paga para mim? Eu não sou mais criança, já sou adulto."

I., (26 anos), uma jovem também com Síndrome de Down, é retratada na fala de outra professora:

Hortência: "I. tem percorrido um monte de escolas porque quando ela fica chateada por sentir que a escola não responde às suas necessidades ela fala: 'Mãe, isso não presta. Vamos embora!' E os pais, primeiro tentavam fazer as professoras entender suas necessidades, mas quando isso não acontecia... iam embora e procuravam outra escola. Então ela tem uma experiência muito grande de mudança de instituição. Na realidade sua postura continua a expressar que a escola tem que mudar. Eu acho que ela já tem certeza de que a escola não vai mudar." 
A professora relata uma experiência de I. em sua última escola.

Hortência: "Tinham um horário para atividades pedagógicas, que se reduzia a copiar, a ler, a escrever algumas coisas, as tarefas de treino da escrita. Isso era o chamado pedagógico (conceito que eu acho deveria ser aprofundado, pois pedagógico pode ser tudo ou nada). $E$ depois no horário da tarde eles tinham oficinas, produção de artesanato. A idéia era eles receberem parte do ganho da produção. O objetivo era que fossem conscientes de que estavam criando essa produção e que eles são cidadãos produtores de uma economia, por isso que a oficina Ihes dava um salário, que era também ínfimo, mas pior ainda, não pagavam. Passavam 3, 4, 5 quinzenas sem receber. Aí um dia I. falou para sua mãe":

- 'Eu estou muito chateada porque não pagam para a gente; você me ajuda?'

- 'Para o que? perguntou a mãe.'

- 'Para fazer um protesto!'

- 'O que você quer protestar?'

- 'Eu quero fazer um cartaz que diga que precisamos que paguem para a gente.'

"Então ela falou o que queria escrever e sua mãe Ihe ajudou para que ela própria escrevesse, e então, foi para a escola com o cartaz. Ela foi muito empolgada, muito feliz, porque ia fazer um protesto na defesa dos interesses dela e de seus colegas. Porque em algumas coisas ela também se preocupava pelos outros que como ela estavam na mesma situação. E chegando na escola a professora da parte pedagógica falou que aquela hora não era de oficina e que ela teria que apresentar aquilo na hora da oficina. I. fez um rolinho com o papel e guardou. Quando chegou a hora da oficina, ela colocou o cartaz, os colegas olharam, a encarregada ficou brava, pegou o cartaz e jogou fora. I. voltou para casa chorando, porque a professora não tinha compreendido. O cartaz dizia: 'Paguem-nos, você gosta que não te paguem?'. Isto era tudo o que falava o cartaz, mas era uma mensagem muito forte, eu acho."

O comportamento de pessoas com Síndrome de Down tem sido comumente comparado ao comportamento infantil e suas necessidades vistas de uma perspectiva infantilizada. Ao falarem sobre a representação histórica da infância, Sarmento, Fernandes e Tomás (2006) afirmam que as crianças ao serem tematizadas na modernidade, foram colocadas numa perspectiva de constituição negativa, pois supostamente a criança não vota, não é responsável por seus atos, não está efetivamente inserida na sociedade, necessitando socializar-se, e mais, "a infância é etimologicamente a idade da não fala (e, por extensão metonímica, a da impossibilidade prática de um discurso legítimo)" (p.143). 
Assim, as falas de F. ao questionar o patrão acerca da insuficiência do "salário" recebido e de se achar competente para recebê-lo, ele mesmo, ao invés de seus pais, e de I. ao reivindicar seu direito e o de seus colegas ao pagamento atrasado não são levadas à sério. A concepção que os assemelha a crianças e os coloca como menos capazes, menos competentes, menos conhecedores da realidade, menos detentores de um saber institucionalizado, reflete-se nas atitudes, nos discursos e nas práticas sociais como "desmerecimento ante aquilo que as crianças dizem ou fazem" (p. 146).

Kruppa (2003, p. 13) define cidadania como "o acesso permanente aos direitos políticos, civis e sociais". E em sua visão, ao se compreender a cidadania como uma relação polarizada entre direitos e deveres, ou seja, os deveres como uma contrapartida natural dos direitos, podem-se cometer alguns equívocos, como por exemplo, acreditar que primeiro existe a necessidade de ser educado ou escolarizado para, após esse dever cumprido, poder exercer os direitos. Para evitar tais equívocos devemos pensar que "o portador de deficiência é cidadão, independentemente do nível de cumprimento dos deveres" (KRUPPA, Ibid., p. 21).

Ao se posicionarem em relação à escola, aos seus direitos, às atividades a que estão submetidos, esses alunos explicitam, pela linguagem, seu posicionamento diante da realidade, evidenciando que muitas coisas não lhes fazem qualquer sentido. Ainda que haja indícios tentando apontar seus interesses, esses indícios não são percebidos por aqueles que desenvolvem seu trabaIho junto a eles, perpetuando práticas infantilizadas que não levam em consideração o que pensam e o que sentem tais sujeitos. Assim, as propostas de alfabetização vivenciadas por F. sempre foram breves e interrompidas, gerando vários e freqüentes sentimentos de frustração.

É importante ressaltar que no caso de F. a necessidade da aprendizagem da escrita e da leitura era essencialmente dele e não da família como forma de satisfação própria ou de status. F. necessitava dessa aquisição até porque vivia num contexto em que as formações acadêmicas na família eram continuadas. Apenas ele não recebera um diploma durante todo esse tempo de escolarização. O diploma para ele tinha o sentido de vencer uma etapa, de estar formado, "pronto" e "preparado" para exercer alguma atividade de trabalho, de ser remunerado, de dar um salto no seu processo de vida escolar.

Violeta: "Quando trabalhava na educação de adultos é uma coisa que a gente já tinha dificuldade de trabalhar, trabalhar no sentido de alfabetizar, que o professor tem que entender que o adulto não é criança e, portanto, eles tinham essa dificuldade na hora de ensinar, pois havia muitos professores que trabalhavam com texto infantil com crianças. Não fazia sentido aquilo, eles têm outras histórias de vida, eles têm outras experiências, são adultos, não são crianças e ninguém leva isso em consideração..." 
Gérbera: "Eles estão sempre sinalizando que o que fazem com eles é inadequado; eles percebem isso, mas os adultos que trabalham com eles, às vezes não percebem..."

Hortência: "E por que será que nós adultos não percebemos o que precisam e o que eles querem?"

Violeta: "No trabalho de educação especial me dá a impressão que há uma concepção social de que eles têm pouca capacidade de aprendizagem. E isso faz com que os professores já partam do princípio de que porque eles têm pouca capacidade de aprendizagem, então não é mais necessário fazer investimento nisso. Como eles vêem que eles têm problemas, não vão aprender, então não investem!"

\title{
[...]
}

Hortência: "Isso que o F. reclamou, ele reclama da exploração e exploração econômica, que é histórica [...] ele tem um sentido de identidade e justiça e do que significa o salário, tanto que ele colocou para a pessoa certa, o patrão."

\section{Considerações finais}

Apesar de a própria família, muitas vezes, acabar tratando os filhos com deficiência de forma infantilizada e como pessoas incapazes de tomar decisões, pois esses foram os sentidos construídos, os professores desses sujeitos também limitam

\begin{abstract}
sua participação a atividades mecânicas e sem sentido para os próprios jovens, reduzindo sua participação, pois segundo as professoras 'há certo tipo de coisas que eles não sabem fazer [...] eles são como crianças [...]. O confisco da alteridade implica que se infantilize ao sujeito, se reconhece o outro, mas como um menor de idade a quem é necessário conduzir, se desconhece a capacidade que tem de fazer suas próprias escolhas ou de resolver os problemas que enfrenta. (ARROYO E ARAÚJO-OLIVERA, 2008, p. 234, 235, tradução nossa)
\end{abstract}

Esses sujeitos, ainda que com seus anunciados "limites", têm a possibilidade de identificar e de expressar as insuficiências nos sistemas de ensino do qual participam, como apreendido na fala de F.: "por que eu não me formo nunca?" Apesar de ser uma fala de F. ela expressa uma realidade social considerando que "uma parte importante dessa população em desvantagem está excluída dos benefícios da educação e do ensino" (ARROYO E ARAÚJOOLIVERA, Ibid., p. 220, tradução nossa) e vivenciam atividades que promovem situações de dependência e de heteronomia.

Ainda segundo as autoras citadas, a maioria das situações vivenciadas por esses jovens no contexto escolar e social prejudica suas possibilidades de 
assumirem-se como cidadãos; além disso, suas possibilidades de sucesso no que diz respeito aos saberes acadêmicos é muito limitada, o que favorece o investimento em atividades manuais pouco valorizadas.

Margarida: "Só para contextualizar meu sentimento... primeiro é que pensei muito no que disseram sobre I. e F.; eu acho que não vivi muito com pessoas com necessidades especiais, e quando a Jasmin colocou sobre pensar no outro, eu nunca me coloquei no lugar do outro com necessidades especiais, eu fiquei imaginando que eu não suportaria não ser ouvida como Síndrome de Down, não daria conta."

A fala dessa professora nos leva a sair de um lugar de conforto para pensar mais detidamente sobre a dificuldade que os sujeitos com alguma deficiência tem tido para serem protagonistas nos cenários sociais e que ficou evidente nas falas dos sujeitos trazidos neste trabalho. Apesar de serem expressões individuais apontam para uma realidade coletiva, se considerarmos que "todos os nossos enunciados [...], são plenos de palavras dos outros, [...] Essas palavras dos outros trazem consigo a sua expressão, o seu tom valorativo que assimilamos, reelaboramos e reacentuamos" (BAKHTIN, 2003, p. 294,295).

Possibilitar o acesso à escola (seja regular ou especial) de pessoas com qualquer tipo de deficiência não garante, necessariamente, o seu acesso à cidadania nem tampouco o exercício dos seus direitos em diferentes instâncias.

Ao pensar em como jovens com Síndrome de Down se movimentam no interior das instituições escolares chamadas especiais nos indagamos sobre sua real inserção e como ela ainda é bastante questionável também nesses espaços. Quais as práticas escolares às quais esses sujeitos têm sido submetidos? Pensar que a responsabilidade pelos processos de inclusão deles deve ocorrer apenas a partir das escolas regulares é, até certo ponto, uma visão bastante equivocada. Não são apenas elas que necessitam se reestruturar para uma nova demanda em termos de escolaridade dessas pessoas.

As falas desses sujeitos, supostamente limitados e impedidos de participação social ativa, nos parecem brilhantes e inteligentes e apontam para pontos críticos - a limitação, muito mais nossa do que deles em relação aos nossos conhecimentos sobre as suas reais necessidades e possibilidades de participação e de intervenção. Precisamos estar mais atentos ao que eles têm dito com insistência sobre as suas efetivas necessidades de participação educacional e social, pois podem encaminhar para uma nova compreensão sobre as possibilidades de inserção dessas pessoas.

\section{Compactuamos com Padilha (2005)}

Quero "ter olhos para ver", "ter ouvidos para ouvir" na descoberta do sujeito que, apesar do que faz ou do que deixa de fazer e, porque faz e deixa de fazer, é sujeito - nem sempre normal, nem sempre doente; nem sempre com 
limitações, mas com limitações. É sujeito e não doença. É sujeito e não "normal". É sujeito e não "patologia". (p. 2)

Em alguns momentos da escrita deste texto nos parecia que estávamos dizendo o óbvio ou que estávamos repetindo algo já há muito conhecido, entretanto, a pertinência das falas de F e I. e o desejo de anunciar e de fazer ouvir as suas vozes nos fez perceber que a repetição estava na insistência deles em se fazerem ouvir e na nossa insistência em não nos apercebermos desses indícios de cidadania; a repetição estava nos desejos deles de apropriação dos bens culturais produzidos pela humanidade e dos quais eles têm sido insistentemente privados.

Esses sujeitos mostram indícios de superação dos limites que thes são atribuídos na esfera do simbólico e da própria linguagem quando se trata de pessoas com deficiência mental. E parecem-nos indícios fortes... Talvez seja necessário ouvir com mais atenção o que eles têm a nos dizer.

\section{Referência}

ARROYO, M.; ARAÚJO-OLIVERA, S. Dispositivo de formación y subjetivación. El caso de jóvenes portadores de Síndrome de Down. In: YURÉN, T.; ROMERO, C. (coordinadoras). La formación de los jóvenes en México: dentro e fuera de los límites de la escuela. Casa Juan Pablos: México, 2008.

BAKHTIN, M. Estética da criação verbal. 4 ed. São Paulo: Martins Fontes, 2003.

2004.

Marxismo e filosofia da linguagem. 11 ed. São Paulo: Hucitec,

CARVALHO, M. de F. Aspectos da dinâmica interativa no contexto da educação de crianças e jovens com síndrome de Down. In: GÓES, M. C. R.; SMOLKA, A. L. B. (Orgs.).In: A significação nos espaços educacionais. Campinas: Papirus. 1997.

DE CARLO, M. M. R. do Prado. Se essa casa fosse nossa...: instituições e processos de imaginação na educação especial. São Paulo: Plexus. 1999.

FERREIRA, M. C. C.; FERREIRA, J. R. Sobre inclusão, políticas públicas e práticas pedagógicas. In: GÓES, M. C. R. de.; LAPLANE, A. L. F. de (Orgs.). Políticas e práticas de educação inclusiva. Campinas, S.P.: Autores Associados, 2004.

GLAT, R. A integração social dos portadores de deficiência: uma reflexão. 3ed. (Coleção Questões atuais em Educação Especial I) Rio de Janeiro: Ed. 7 Letras, 2004.

KASSAR, M. de C. M.. Modos de participação e constituição de sujeitos nas práticas sociais: a institucionalização de pessoas com deficiência múlti- 
pla. 1999. 123 f. Tese (Doutorado em Educação). Faculdade de Educação da UNICAMP, Campinas, 1999.

. Matrículas de crianças com necessidades educacionais especiais na

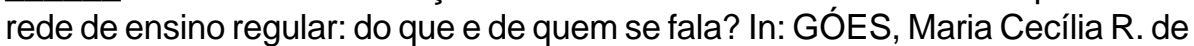
e LAPLANE, Adriana L. F. de (Orgs.). Políticas e práticas de educação inclusiva. Campinas, S.P.: Autores Associados, 2004.

KRUPPA, S. M. Portella. As linguagens da cidadania. In: SILVA, S.; VIZIM, M. (Orgs.). Educação especial: múltiplas leituras e diferentes significados. Campinas: Mercado de Letras: Associação de Leitura do Brasil (ALB), 2003.

NEVES, T. R. L. Movimentos sociais e cidadania: quando a pessoa com deficiência mental fala na primeira pessoa do singular. In: SILVA, S.; VIZIM, M. (Orgs.). Políticas públicas: educação, tecnologias e pessoas com deficiências. Campinas: Mercado de Letras: Associação de Leitura do Brasil (ALB), 2003.

SARMENTO, M. J.; FERNANDES, N.; TOMÁS, C. Participação social e cidadania ativa das crianças. In: RODRIGUES, D. (Org.). Inclusão e educação: doze olhares sobre a educação inclusiva. São Paulo: Summus, 2006.

SKLIAR, C. A inclusão que é "nossa" e a diferença que é do "outro". In: RODRIGUES, D. (Org.). Inclusão e educação: doze olhares sobre a educação inclusiva. São Paulo: Summus, 2006.

PADILHA, A. M. L. Práticas Pedagógicas na educação Especial: a capacidade de significar o mundo e a inserção cultural do deficiente mental. 2.ed. Campinas: Autores Associados, 2005.

VYGOTSKY, L. S. Obras escogidas. Problemas de psicologia general. Madri: Visor Distribuciones, 1993. v. 2.

Obras escogidas. Problemas del desarrollo de la psique. Madri: Visor Distribuciones, 1995. v.3

VYGOTSKY, Liev Semiónovitch. Problemas fundamentales de la defectologia. In: VYGOTSKY, L. S. Fundamentos de defectologia. Havana: Pueblo y Educación, p. 2-26, 1989.

Notas

${ }^{1}$ Skliar (2006), ao discutir sobre a questão da diferença, afirma que há uma confusão no contexto pedagógico entre a "diferença" e o "diferente". Segundo ele, os "diferentes respondem a uma construção [...] de categorização, separação e diminuição de alguns traços, de algumas marcas, de alguns sujeitos [...] em relação ao vasto e por demais caótico conjunto de diferenças humanas" (p.23), enquanto as diferenças não podem ser categorizadas e nem evidenciar marcas que se posicionem contrariamente à idéia de uma "norma".

2 Essas são as idades dos sujeitos à época dos encontros (2007).

${ }^{3}$ É importante ressaltar que apesar de acompanharmos as mudanças na terminologia preferimos manter aqui o termo deficiência. Não negamos que as novas nomenclaturas avançam no sentido de apontar para novas ênfases, novas posturas e ações práticas. Acontece que mudar apenas 
a forma de chamar esses sujeitos (com deficiência ou com necessidades educativas especiais ou que apresentam necessidades educacionais especiais), não muda, necessariamente, a maneira de vê-los, de tratá-los, de educá-los e de inseri-los no meio educativo e social. Além disso, a amplitude e a falta de precisão nas terminologias utilizadas, na maioria das vezes, mais confundem do que ajudam.

\section{Correspondência}

Eliana Prado Carlino - Rua Maria Aparecida Bueno Barbosa, 849. Centro. CEP 13630-225. Pirassununga, São Paulo, Brasil.

E-mail: ecarlino@bol.com.br

Recebido em 19 de julho de 2010

Aprovado em 13 de setembro de 2010 